TI 2017-049/VI

Tinbergen Institute Discussion Paper
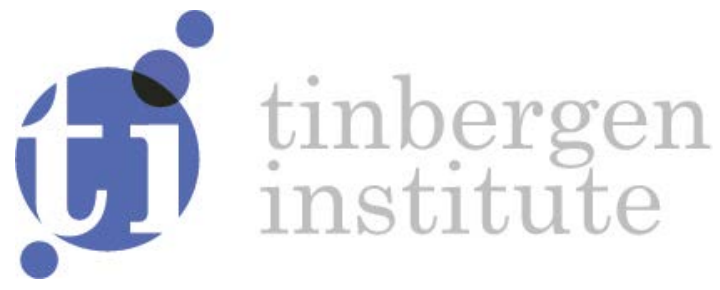

\title{
Real-Estate Agent Commission Structure and Sales Performance
}

Pieter Gautier ${ }^{1}$

Arjen Siegmann ${ }^{2}$

Aico van Vuuren ${ }^{3}$

${ }^{1}$ Vrije Universiteit Amsterdam and Tinbergen Institute

${ }^{2}$ Vrije Universiteit Amsterdam

${ }^{3}$ University of Gothenburg 
Tinbergen Institute is the graduate school and research institute in economics of Erasmus University Rotterdam, the University of Amsterdam and VU University Amsterdam.

Contact: discussionpapers@tinbergen.nl

More Tl discussion papers can be downloaded at http://www.tinbergen.nl

Tinbergen Institute has two locations:

Tinbergen Institute Amsterdam

Gustav Mahlerplein 117

1082 MS Amsterdam

The Netherlands

Tel.: +31(0)205984580

Tinbergen Institute Rotterdam

Burg. Oudlaan 50

3062 PA Rotterdam

The Netherlands

Tel.: +31(0)10408 8900 


\title{
Real-Estate Agent Commission Structure and Sales
}

\author{
Performance
}

Pieter Gautier* Arjen Siegmann ${ }^{\dagger} \quad$ Aico van Vuuren ${ }^{\ddagger}$

This version: February 2017

\begin{abstract}
Do higher real-estate agent fees imply better performance? This study uses a nation-wide data set of residential real-estate transactions in the Netherlands from 1985 to 2011 to provide evidence against this. Brokers with a flat-fee structure who charge an up-front fee (which is substantially lower than the average fee of traditional brokers) and leave the viewings to the seller sell faster and at - on average -2.7 percent higher prices. We correct for fixed houseand time effects. We provide additional evidence that the price difference is not due to a seller-selection effect.
\end{abstract}

Keywords: real-estate brokers, broker incentives, housing, agency

JEL-Classification: D80, L10, L80, R20, R30

*Vrije Universiteit Amsterdam.

†Vrije Universiteit Amsterdam, Corresponding author, a.h.siegmannvu.nl.

$\ddagger$ University of Gothenburg.

The authors thank Johan Walden, seminar participants at the VU and the European Finance Association 2016 for useful comments and suggestions. We thank NVM, the "Nederlandse Vereniging van Makelaars o.g. en vastgoeddeskundigen" for providing the data. 


\section{Introduction}

The majority of residential home sales is realized through the help of a real-estate agent. ${ }^{1}$ This is not surprising because both buying and selling a home involve decisions that can have a large and long-lasting financial impact, and consumers are typically not well informed about the real-estate market. However, real-estate agents are expensive: a typical real-estate agent who represents the seller charges 6 percent of the sales price in the US, while the fee is between 2 and 3 percent in the UK and about 2 percent in the Netherlands. ${ }^{2}$ According to White (2007), 61 billion dollars were spent on real-estate transaction fees in 2004 in the US. ${ }^{3}$ Whether or not those fees are excessive is an empirical question that we address in this paper. If real-estate agents are very good in bringing (heterogeneous) sellers and buyers together, they create surplus that could in principle justify high fees. So in order to create surplus, real-estate agents should sell faster and/or at a higher price.

This paper addresses the performance of real-estate agents using a unique case study for the Netherlands. In contrast to the US, almost all of the residential property for sale is listed publicly in the Netherlands (as of 2001) on an internet site called Funda. Originally, only traditional full-service brokers posted the houses of their clients on this website and charged a fee of around 2 percent, payable after the transaction was made (the average transaction price was almost 200,000 Euro). In 2005, flat-fee brokers entered the market. These brokers charge an up-front fee,

\footnotetext{
${ }^{1}$ According to realtor.org, 89 percent of home sellers in the United States use a real-estate agent, while this number is 87 percent for home buyers.

${ }^{2}$ Note that in the US, the 6 percent also includes the fee that the real-estate agent of the seller needs to pay to the real-estate agent of the buyer.

${ }^{3}$ Based on the data provided on realtor.org, we obtain a figure of 70 billion dollars for 2015 . This conjecture is fed by the fact that most countries have a brokerage fee which is a fixed percentage of the sales price. See OECD (2007) for a complete list of brokerage fees.
} 
in the range of 400 to 1300 Euro, which is only a fraction of the average fee of the traditional brokers. In addition to charging a flat fee, these brokers use the same online multiple listing service as the traditional brokers. Moreover, they offer limited additional services, such as price negotiation. The main difference with traditional brokers is that they leave the viewings of the house to the seller.

We find the flat-fee strategy to be the only broker characteristic that is significant in explaining differences in transaction prices and time to sell. Other broker properties such as proximity, experience and size have no significant effect on these outcomes. Houses sold through a flat-fee broker obtain a 2.7 percent higher price and sell significantly faster. The difference in transaction prices is almost unresponsive to alternative specifications, such as conditioning on high- and low prices, the type of house and the density of houses for sale in the same neighborhood. We also do not find that homeowners who switch from a flat-fee broker to a traditional broker obtain a significantly higher price than those who started with a traditional broker. This rules out simple explanations such as differences in price or liquidity of the house or selection of unobservable house characteristics.

Our paper is related to Hendel et al. (2009), who look at the difference in price and time on the market between the realtors' MLS and a for-sale-by-owner (FSBO) website in Madison. Given that all of our transactions take place on the same platform, we are able to single out the impact of the additional services provided by the traditional real-estate agents rather than a combination of services and quality of the platform. Hendel et al. (2009) find that houses that are originally listed on an FSBO website sell at a higher price no matter whether those houses are sold through the realtors' MLS or through the FSBO website, while we find that traditional realestate agents who receive a percentage of the selling price sell at a lower price than 
the flat-fee agents. In section 5 we show that it is unlikely that our results are driven by the fact that sophisticated sellers sort into flat-fee brokers or are the result of censoring.

Our paper is also related to Bernheim and Meer (2013), who look at houses sold at the university campus of Stanford. Similar to the paper of Hendel et al. (2009), they compare FSBO sales with brokered sales. However, in contrast to Hendel et al. (2009), but in line with our research, the Stanford study listed all campus sales on one single open-access listing service, which is available regardless of whether a broker is used or not. One caveat of the paper of Bernheim and Meer (2013) is that the number of observations is low and the Stanford housing market may not be representative for the total population because homeownership at the campus is limited to Stanford faculty and some senior staff. Nevertheless, an advantage of their analysis is that the sellers are a relatively homogeneous group, which reduces the risk of seller selection into FSBO sales. Our group of sellers is more heterogeneous, but also in our study the risk of seller selection is small because sellers that use flat-fee brokers only perform a relatively simple task: providing the viewings of the house. Therefore, differences in negotiation skills between buyers and the potential stigma of FSBO sales cannot explain our results.

We also contribute to the literature on potential agency problems for delegated brokers in real estate (see Rutherford and Yavas, 2012, Han and Hong, 2011, Bergstresser et al. 2009, and Del Guercio et al., 2010). Our result of a 2.7 percent difference in transaction performance is substantial - and obviously larger than the opportunity costs of the time spent when someone decides to sell the house through a low-service flat-fee broker. The result for flat-fee brokers is similar in size to that of brokers who sell a house that they own themselves; see Rutherford et al. (2005) and 
Levitt and Syverson (2008b). The higher price obtained by a broker-owner can be explained by the superior information available to the broker and the higher effort level he or she expands. Finally, our results are relevant for the literature on the role of platforms in intermediation; see Hendel et al. (2009). Our results suggest that once houses are listed on a platform, a simple structure of a flat fee and minimal additional services performs very well in terms of a high transaction price and fast sale.

We find no evidence that brokers with offices located in the proximity of the seller perform better. This contrasts with earlier studies on the relation between geographical proximity and investor performance by stock investors, hedge funds, investors in municipal bonds and investors in mutual funds; see Teo (2009) and Butler (2008). Ivkovic and Weisbenner (2005) find that households have a strong preference for stocks that are geographically close. Moreover, they find that local investors seem to have some degree of superior information.

The rest of this paper is organized as follows. Section 2 describes the institutional aspects of real-estate brokerage in the Netherlands. Section 3 describes the data. Section 4 describes the empirical approach and estimates. Section 5 provides additional robustness analyses. Section 6 discusses some potential explanations for our main results. Section 7 concludes.

\section{Real-estate agents in the Netherlands}

In the Netherlands, real-estate agents can work independently, but most are members of a real-estate association. The largest association is the National Association of Real-Estate Brokers and Real-Estate Valuers (NVM), to which seventy percent 
of all real-estate agents belong. In terms of transactions, NVM had a 75 percent market share measured over 2010 and 2011.

In January 2001, NVM launched a website, funda.nl, where all the houses of its members are listed. Funda quickly became the dominant platform for potential buyers, as it eliminated the need for a buy-side broker and made all the houses and their details visible for free. In 2010, Funda started to list houses of non-NVM agents as well.

Before 1999, NVM had a recommended fee of around 2 percent of the sales price. ${ }^{4}$ The recommended fee was abolished in 1999, under the threat of sanctions from the anti-trust authority. Still, although the fees have been decreasing in terms of the percentage of the sales price, anecdotal evidence suggests that many agents continue to use fees close to 2 percent. In addition, brokers are reluctant to negotiate the fee and, with the exception of the flat-fee brokers, they do not openly compete on price.

Starting in 2005, flat-fee brokers entered the market as members of the brokers association. They charge an up-front, fixed fee. At the moment of our research, the fee of these brokers was in the range of 400 to 1300 Euro. In return, they list a house on Funda, advise on the list price and perform the negotiation. The major difference with a traditional broker is that the viewing of the house is scheduled and hosted by the seller.

In response to the Funda platform, some so-called for-sale-by-owner websites have sprung up where sellers list their house directly, without the intermediation of a broker. However, in contrast to other countries (such as the US), this has not caught on in a significant way (Hendel et al., 2009, and Bernheim and Meer, 2013).

\footnotetext{
${ }^{4}$ The recommended fee was 1.85 percent excluding VAT.
} 


\section{Data}

The data set of transaction prices, obtained from the NVM, contains the properties of houses and apartments sold between 1985 and 2011, as well as a unique identifier for the real-estate agent. The data set does not contain objects that are rented out. Note that the use of this data set implies that we do not observe transactions that are not represented by a broker that is a member of the association. Nevertheless, the benefit of using this data set is that all of our transactions since 2001 were listed on the Funda website, which guarantees the use of one and the same platform for every house sale in our data set.

Starting from 2,007,914 transactions, we remove observations with missing house size (in square meters) and missing lot size (if not an apartment). Then, the following filters are applied: we discard observations with a list price or transaction price below ten thousand Euro and above one hundred million Euro, an absolute percentage change in transaction price relative to list price of more than fifty percent, a size of less than twenty square meters, and selling date equal to or before list date. Also, we discard observations with other obvious errors. Furthermore, we remove observations with brokers for which we were unable to find their associated profile (see below) and transactions on houses that have not sold since 2005 (i.e., the year in which flat-fee commission brokers became active). ${ }^{5}$ We also delete 327,097 transactions that represented a house that is only sold once in our data set and therefore drops out of our analysis since we use house fixed effects in all of our regression equations of Section 4. This leaves us with 380,252 observations which are

\footnotetext{
${ }^{5}$ We cannot remove all observations prior to 2005, as we need them to allow for house fixed effects.
} 
Table 1: Number of observations per house

\begin{tabular}{lr}
\hline $\begin{array}{c}\text { Number of } \\
\text { observations } \\
\text { per house }\end{array}$ & $\begin{array}{c}\text { Number of } \\
\text { houses }\end{array}$ \\
\hline \hline 2 & 118,309 \\
3 & 33,834 \\
4 & 7,907 \\
5 & 1,641 \\
6 & 301 \\
7 & 61 \\
8 & 6 \\
9 & 2 \\
& \\
Total & 162,061 \\
\hline \hline
\end{tabular}

represented by 162,061 houses. Table 1 lists the number of observations per house.

The evolution of average prices and number of transactions appears in Figure 1.

\subsection{Broker identification and characteristics}

Each transaction in the data provides the identification number for the broker that sold the house; this number has an associated broker profile on the online multilisting service. The profile gives the address, website and a short description of each broker.

Besides the flat-fee strategy that we discuss first, we define four other characteristics of brokers that may affect transaction price and duration: (i) the fee strategy, (ii) proximity to the house, (iii) size and (iv) experience. ${ }^{6}$

\footnotetext{
${ }^{6}$ We use dummy variables to reduce noise, but the results remain qualitatively similar if we use log-linear variables for proximity, size and experience.
} 
Figure 1: Transaction prices and volume, 2005-2011

This figure shows the price growth (solid line, left-hand axis) and volume (column, righthand axis) from January 2005 to June 2011 per quarter in which the sale occurs.

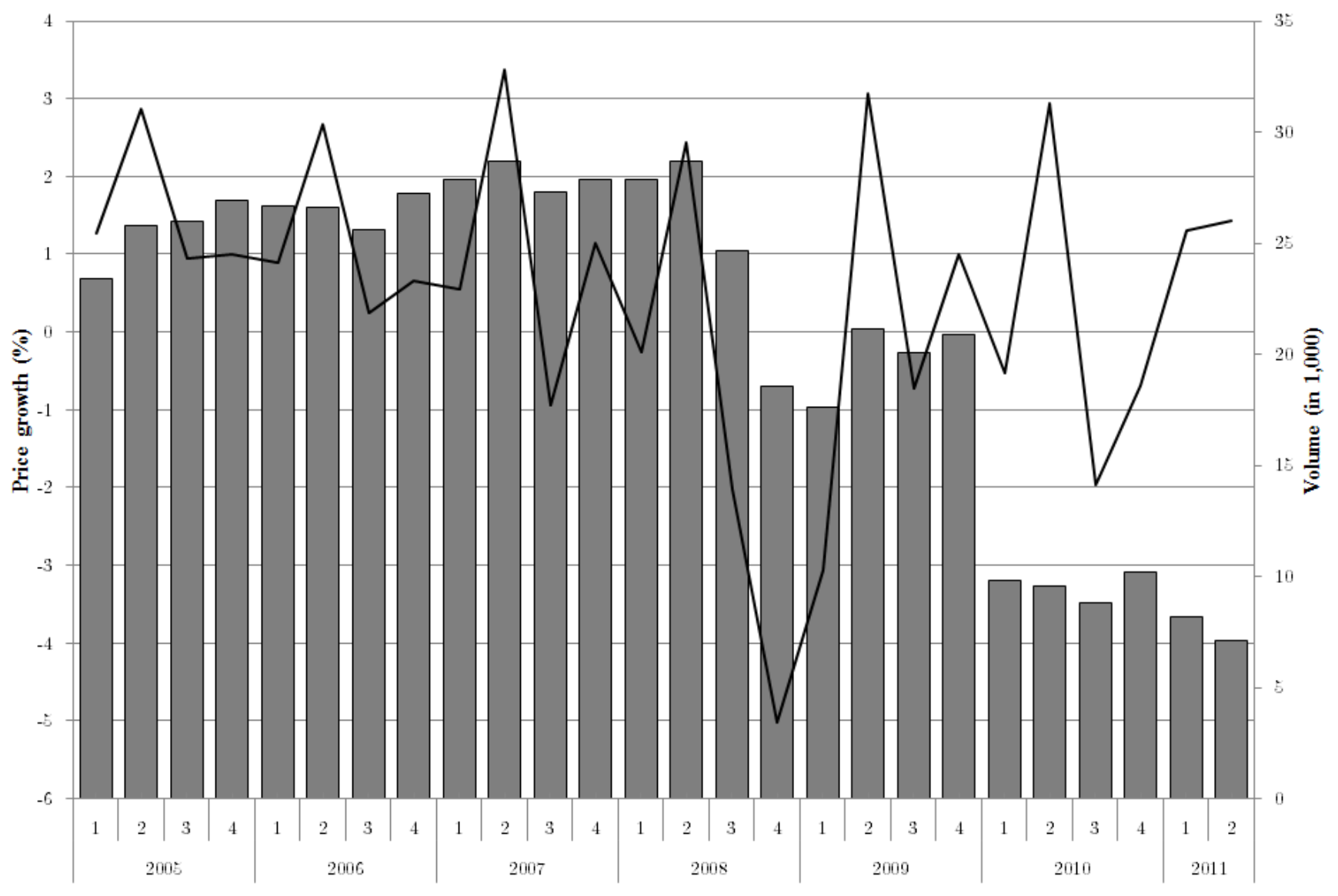




\section{$3.2 \quad$ Fee strategy}

The listing platform has a separate section that lists brokers. We use the search phrase "flat fee" to find the brokers who advertise with a flat-fee structure and identify a total of thirteen brokers with a total market share of 2.3 percent of all transactions since 2005 (i.e., the year in which they first became active). The brokers are active throughout the country and this is reflected in the transactions (i.e., flatfee transactions are not limited to one or a few specific regions).

\subsection{Proximity}

To find the geographical location of the broker, we take the address on the broker's profile page and feed it into a geocoding service in order to obtain the $x$ and $y$ spatial coordinates. The geocoding was done in 2011 and 2012 to minimize the measurement errors from relocations of real-estate agents. We compute the absolute distance between each object and its broker using the $x$ and $y$ spatial coordinates. The dummy variable 'Close-by' is 1 if the house is within the smallest 20 th percentile of distances between houses and brokers, which is approximately 800 meters.

\subsection{Size}

We compute the number of transactions per broker, per year, and determine large brokers as those with a size above the 80th percentile.

\subsection{Experience}

We define the experience of a broker as the difference between the current year and the first year that a broker has sold a house. The dummy variable 'Experienced' is 
Table 2: Summary statistics of the dependent variables.

\begin{tabular}{lrrr}
\hline \hline & Mean & Median & $\begin{array}{r}\text { Standard } \\
\text { deviation }\end{array}$ \\
\hline Initial list price & 208,256 & 189,500 & 107,738 \\
Last list price & 205,021 & 189,000 & 105,291 \\
Transaction price & 197,244 & 180,000 & 100,700 \\
Percentage difference & & & \\
$\quad$ with last list price & -3.7 & -3.4 & 3.7 \\
Days to sell & 115 & 64 & 138 \\
\hline \hline
\end{tabular}

1 if the broker associated with the transaction has an experience which is above the highest 80th percentile of experience.

Table 2 presents the summary statistics of the transactions in our data set. We observe that the average difference between the last listed price and the transaction price is -3.7 percent. Note that, in contrast to the situation in the US, the list price does not involve any legal obligation to sell in the Netherlands. The average time on the market is 115 days, while the median duration is 64 days. The high mean relative to the median indicates that the distribution of sales times is skewed to the right. This is consistent with stock-flow models of the housing market; a new seller either sells fast to buyers from the stock or, if she does not immediately sell, she awaits the arrival of new buyers (flow) (see Coles and Smith ,1998).

Table 3 lists the descriptive statistics of our regressors. The average distance to the broker is 2.78 miles with a median of 1.19 miles. This indicates that real-estate agents operate in a local market and suggests preferences from sellers to choose an agent that is close by. A total of 12,136 transactions are carried out by brokers that use a flat-fee strategy, which is 1.7 percent of the total transactions that we use for our panel estimation for the whole period. The market share of flat-fee brokers is 2.3 percent in the sample of houses sold since 2005. Our sample contains both 
Table 3: Summary statistics of the regressors

\begin{tabular}{lr}
\hline \hline Lot size (only houses) & 164 \\
& $(694)$ \\
Surface area $\left(\mathrm{m}^{2}\right)$ & 107 \\
& $(36)$ \\
Volume $\left(\mathrm{m}^{3}\right)$ & 313 \\
& $(123)$ \\
Distance to broker (in miles) & 2.78 \\
& $(7.38)$ \\
Flat-fee broker & 0.017 \\
Apartment & 0.370 \\
Elevator & 10.5 \\
Number of floors & 2.24 \\
& $(0.89)$ \\
Number of rooms & 4.16 \\
& $(1.25)$ \\
Attic & 0.242 \\
Loft & 0.073 \\
Roof terrace & 0.06 \\
Has more than 1 toilet & 0.780 \\
Has more than 1 bathroom & 0.023 \\
Has a garage & 0.228 \\
Garden maintenance (subjective 1-5) & 3.35 \\
& $(0.79)$ \\
Maintenance inside (subjective 1-10) & 7.02 \\
& $(1.03)$ \\
Maintenance outside (subjective 1-10) & 7.04 \\
& $(0.89)$ \\
Insulation level (subjective 1-5) & 1.96 \\
& $(1.71)$ \\
Modern heating & 0.907 \\
Has open view & 0.273 \\
Next to busy road & 0.036 \\
Basement & 0.023 \\
Is a monument & 0.005 \\
\hline Quarter of sale & 26.8 \\
\hline January-March & 27.0 \\
April-June & 24.1 \\
July-September & 22.1 \\
October-December & \\
\hline \hline
\end{tabular}


multi-floor houses and apartments. A seasonal effect is visible in the lower number of houses sold in the fourth quarter (22 percent) relative to the first (27 percent).

\section{Empirical Analysis of the Broker Effect}

\subsection{Panel Estimation}

We use the following model to investigate the effect of broker characteristics on the transaction price and sales time:

$$
\log Y_{i t}=X_{i t} \beta+k_{p(i) t}+Z_{i t} \gamma+\eta_{i}+\mu_{i t}+U_{i t}
$$

where $Y_{i t}$ is the dependent variable of interest (either the transaction price or the sales time) of house $i$ in year $t$ in province $p ; X_{i t}$ contains the characteristics of house $i$ at time $t$, including the quarter in which it is sold (see Table 2). $k_{p t}$ captures region-specific variation in annual prices and $Z_{i t}$ contains the four broker dummies: flat fees, located close by, large and experienced. The final three terms are the fixed house effect $\left(\eta_{i}\right)$, the time-varying house-specific effect $\left(\mu_{i t}\right)$, and the residual $\left(U_{i t}\right)$. The fixed house effect contains anything that is affecting the sales price, but which is not captured in $X_{i t}$ and which does not change over time. The time-varying house-specific effect $\mu_{i t}$ contains any time-varying house characteristics not captured by $X_{i t}$ and $\eta_{i}$, such as the time between two sales, buyer and seller characteristics, and unobserved characteristics of the house not captured by the other variables. The error term $U_{i t}$ is assumed to be independent of all observed and unobserved characteristics.

We control for seasonality by including dummy variables for the different 
quarters as controls. We use an apartment-specific surface measure $\left(\mathrm{m}^{2}\right)$ as apartments lack some characteristics that houses have, such as the lot size and garden, which might influence the shadow price of surface for apartments. As the time between consecutive sales might affect pricing, we also include a variable that measures the time in years since the previous sale of the house. All quantity variables in $X_{i t}$ are in logs. We use twenty-two regional dummy variables for the construction of $k_{p(i) t}$ in (1): ten for the largest cities and twelve for the provinces in the Netherlands.

The error term, $U_{i t}$, is assumed to be independent and identically distributed. The model in (1) is similar to that of Levitt and Syverson (2008b) and Rutherford et al. (2005), except that we have the broker variables as additional explanatory variables.

The parameters in equation (1) can be estimated using fixed effects under the condition that time-varying house-specific effects are absent or that they are not correlated with any of the observed characteristics, including the seller's choice to use a flat-fee real-estate broker. This is also the strategy used, for example, in Hendel et al. (2009). We discuss these assumptions in the next Sections.

Our results are presented in Tables 4 to 6 , where we have multiplied the coefficients by 100. Table 4 lists the results for the transaction prices and shows that controlling for house fixed effects, region-year interactions and agent characteristics, a flat-fee agent is associated with a 2.7 percent higher transaction price. Our estimates imply that the benefits for the mean seller in the period 2005-2011 (house value of 197,244 Euro) of using a flat-fee broker are substantial. Apart from the lower fee paid by sellers using a flat-fee broker, sellers gained more than 5,300 Euro in terms of a higher transaction price relative to those who used a traditional broker. 
Table 4: Estimation results for the log transaction price

Estimated coefficients on the broker dummy variables for regressions of the transaction price. The sample period is 1985-2011, using houses that sold at least once since 2005. Only the coefficients on the broker dummies are reported (multiplied by 100). Neighborhood clustered standard errors appear between parentheses. *, $* *, * * *$ denote significance at the $90 \%, 95 \%$ and $99 \%$ levels, respectively.

\begin{tabular}{lcccc}
\hline \hline & $(1)$ & $(2)$ & $(3)$ & $(4)$ \\
\hline Flat-fee broker & $2.38^{* * *}$ & $2.77^{* * *}$ & $2.73^{* * *}$ & $3.03^{* * *}$ \\
& $(0.39)$ & $(0.49)$ & $(0.49)$ & $(0.54)$ \\
Close by & & 0.032 & 0.033 & 0.12 \\
& & $(0.29)$ & $(0.29)$ & $(0.33)$ \\
Experienced & & $0.74^{*}$ & $0.72^{*}$ & 0.53 \\
& & $(0.44)$ & $(0.43)$ & $(0.45)$ \\
Large & & -0.12 & -0.10 & -0.12 \\
& & & & \\
Time between (in log) & & & $(0.20)$ & $(0.22)$ \\
& & & & \\
& Yes & Yes & Yes & Yes \\
House fixed effects & Yes & Yes & Yes & No \\
House characteristics & Yes & Yes & Yes & Yes \\
Region $\times$ year dummies & & & & \\
& & & & \\
$R^{2}-$ within & 0.935 & 0.935 & 0.935 & 0.920 \\
\hline \hline
\end{tabular}

Table 5 lists the results for the list prices. In line with the results presented in Bernheim and Meer (2013), we find that the lower selling prices can be completely explained by the lower list prices.

Table 6 lists the results for the time to sale. The higher transaction price that flat-fee brokers realize is, surprisingly, associated with shorter sales times. The coefficient is large, at $-18 \%$, suggesting a sales time that is roughly 21 days shorter than the median sales time of 115 days for all transactions since 2005. The results in Table 6 suggest that some of the other broker characteristics are also important for sales time. Large and nearby brokers sell houses faster. Our data suggests that there is no obvious trade-off between sales time and transaction price. This contrasts with 
Table 5: Estimation results for the log initial list price

Estimated coefficients on the broker dummy variables for regressions of the transaction price. The sample period is 1985-2011, using houses that sold at least once since 2005. Only the coefficients on the broker dummies are reported (multiplied by 100). Neighborhood clustered standard errors appear between parentheses. *, $* *, * * *$ denote significance at the $90 \%, 95 \%$ and $99 \%$ levels, respectively.

\begin{tabular}{lc}
\hline \hline & $(1)$ \\
\hline Flat-fee broker & $2.62^{* * *}$ \\
& $(0.50)$ \\
Close by & -0.13 \\
& $(0.29)$ \\
Experienced & $0.85^{*}$ \\
& $(0.43)$ \\
Large & $-0.36^{*}$ \\
& $(0.21)$ \\
Time between (ln) & $0.25^{* * *}$ \\
& $(0.051)$ \\
& \\
House fixed effects & Yes \\
House characteristics & Yes \\
Region x year dummies & Yes \\
$R^{2}-$ within & 0.932 \\
\hline \hline
\end{tabular}

Levitt and Syverson (2008b) and Rutherford et al. (2005), which have longer sales times associated with a higher price. Finally, note that for the time on the market, the fit and precision is less than for the price estimates.

Leaving out the house characteristics, as in column (4) of Tables 4 and 6 gives almost identical estimates and the reduction in $R^{2}$ is minimal. It shows that the year dummy variables pick up almost all of the price variation that is not related to the broker. This is explained by the fact that the most important characteristics, such as surface and volume of the house, do not change much over time.

We also test for higher order and interaction effects of our controls, and our main result remains qualitatively similar (i.e. the coefficient for a flat-fee strategy 
Table 6: Estimation results for the log time to sale

Estimated coefficients on the broker dummy variables for regressions of the transaction price. The sample period is 1985-2011, using houses that sold at least once since 2005. Only the coefficients on the broker dummies are reported (multiplied by 100). Neighborhood clustered standard errors appear between parentheses. *, $* *, * * *$ denote significance at the $90 \%, 95 \%$ and $99 \%$ levels, respectively.

\begin{tabular}{lcccc}
\hline \hline & $(1)$ & $(2)$ & $(3)$ & $(4)$ \\
\hline Flat-fee broker & $-24.0^{* * *}$ & $-18.3^{* * *}$ & $-18.4^{* * *}$ & $-18.1^{* * *}$ \\
& $(4.32)$ & $(4.60)$ & $(4.60)$ & $(4.62)$ \\
Close by & & $-5.09^{* * *}$ & $-5.09^{* * *}$ & $-5.03^{* * *}$ \\
& & $(1.92)$ & $(1.92)$ & $(1.92)$ \\
Experienced & & $3.85^{* *}$ & $3.83^{* *}$ & $3.78^{* *}$ \\
& & $(1.54)$ & $(1.53)$ & $(1.53)$ \\
Large & & $-7.15^{* * *}$ & $-7.12^{* * *}$ & $-7.01^{* * *}$ \\
& & $(1.78)$ & $(1.78)$ & $(1.78)$ \\
Time between (in log) & & & $0.50^{* * *}$ & $0.51^{* * *}$ \\
& & & $(0.15)$ & $(0.15)$ \\
House fixed effects & Yes & Yes & Yes & Yes \\
House characteristics & Yes & Yes & Yes & No \\
Region $\times$ year dummies & Yes & Yes & Yes & Yes \\
$R^{2}-$ within & & & & \\
\hline \hline
\end{tabular}

remains significant and in the range of 2 to 3 percent). The same holds for removing the largest flat-fee broker from the sample (i.e., our results are not caused by having one particularly high-performing broker).

The positive coefficient for the (log) time between consecutive transactions in Tables 4 and 5 indicates a seller-specific effect. This could be caused by older sellers who are less likely to be credit constrained and thus more patient; see Albrecht et al. (2016). This is consistent with a positive relation between the sales time and the time between the two sales; see Table 6 .

Finally, note that the house fixed effects control for the exact location of the house and other subjective elements that are difficult to measure quantitatively. 
Moreover, the houses are all listed on the same online platform, so that the network effects of different platforms or sellers are not driving our results. Thus, our results reported in Tables 4 to 6 cannot be explained by an information effect: the sellers involved in these transactions have exactly the same information.

\section{Robustness}

\subsection{Interaction effects}

The hedonic model in (1) might be misspecified with regard to nonlinear relations between house characteristics and (log) prices. We can control for this by introducing interactions of variables of interest with the flat-fee dummy.

The first interaction concerns price. Expensive houses might be underpriced in the log-linear hedonic model and sold more often by a flat fee. In that case, the coefficient in the full sample might be driven by a limited number of expensive houses with a successful house sale using a broker with a flat-fee strategy. Also, given that a traditional fee is a percentage of the transaction price, the monetary incentives to choose a broker that uses a flat-fee strategy are higher for more expensive houses. In order to investigate this, we interact an above-median price dummy with the flat-fee broker dummy.

A second concern is that apartments and houses in high-density areas could be overrepresented in the sample of houses that are sold through the use of a flat-fee broker. Apartments are easier to price, since they have fewer unique characteristics, making it possible to find almost identical objects (such as apartments in the same building that have been sold before). Likewise, sellers in neighborhoods with a high- 
density of houses might find it easier to set a list price based on comparable objects and be more inclined to choose a flat-fee broker. We control for these effects by interacting the flat-fee dummy with the dummy variable for apartments and the dummy variable for above-median neighborhood densities.

A third concern is that sophisticated sellers are more likely to sell using a cheaper flat-fee real-estate agent. We expect that this selection effect would be largest in the earliest years of the introduction of flat-fee real-estate agents, since the most sophisticated sellers are also the ones who are most likely to be early adopters of the new selling strategy. Moreover, the number of sales made with flat-fee realestate agents has been increasing over time, which immediately implies a decrease in the selectivity of the sophisticated sellers. This hypothesis implies that we should expect a declining impact of flat-fee brokers since their introduction in 2005 . We test this by interacting the flat-fee dummy with a dummy that is 1 in the years prior to 2008.

A fourth issue is that traditional real-estate agents could be exerting more effort in the fourth quarter in order to meet their annual sales target. This effect is absent under a flat fee, where fees are earned up-front. We therefore interact our flat-fee dummy with a dummy for the fourth quarter.

A final concern is that the distribution of sales times could be more fat-tailed for those sales involving the help of a flat-fee broker. That is, traditional brokers would be more effective for difficult-to-sell houses, while a flat-fee structure would be better for liquid properties. To test this, we interact with a dummy variable that is 1 if the sales time is higher than the median. Note that the interpretation of this variable is complicated by the fact that sales time is endogenous. That is, unobserved characteristics that affect the sales time also affect the selling price of 
the house. Nevertheless, due to the expected negative relationship between the two outcome variables, the absolute value of the coefficient estimates can be interpreted as an upper bound of the real effect.

Table 7 reports the estimation results for transaction prices with interaction effects. The conclusion that can be drawn from this Table is that in all alternative specifications, the positive flat-fee effect remains. The only statistically significant terms are the ones with sales time and the fourth quarter dummy. The sales-time effect is such that flat-fee houses sell 4.1 percent faster. For longer sales times, the performance is reduced to 1.3 percent, but as stated in the previous paragraph, this can be interpreted as a lower bound. If anything, this indicates that even houses with a long time to sale obtain a higher price when using a flat-fee broker. The fourth-quarter effect suggests that traditional brokers put more effort into selling a house in the fourth quarter, reducing the performance gap with fixed-fee brokers to 1.5 percent $(3.07-1.64)$. This supports an end-of-year effect on the part of realestate agents aiming to reach a sales target. Such effects exist in many industries where compensation schemes depend on yearly sales in a non-linear way; see Oyer (1998). To summarize, the evidence points to a sizable and significantly positive effect associated with a flat fee on the part of the seller that is not explained by interactions with other variables.

\section{$5.2 \quad$ Sellers switching agents}

As in the analysis of Hendel et al. (2009), another way to investigate the selection effect of sellers is to look at the sellers who initially started with one type of broker (for example, a flat-fee broker) and then switched to another type (say, a traditional 
Table 7: Interaction effects

Estimated coefficients on the broker dummy variables for panel regressions of transaction price on house- and broker characteristics. The sample period is 1985-2011, using houses that sold at least once since 2005. Only the coefficients on the broker dummies are reported, multiplied by 100 . Clustered standard errors appear between parentheses. *, **, *** denote significance at the $90 \%, 95 \%$ and $99 \%$ levels, respectively.

\begin{tabular}{|c|c|c|c|c|c|c|c|}
\hline & (1) & $(2)$ & $(3)$ & $(4)$ & $(5)$ & $(6)$ & $(7)$ \\
\hline Flat-fee broker & $\begin{array}{l}2.55^{\text {*** }} \\
(0.72)\end{array}$ & $\begin{array}{l}2.87^{* * *} \\
(0.61)\end{array}$ & $\begin{array}{l}2.71^{* * *} \\
(0.78)\end{array}$ & $\begin{array}{l}4.11^{* * *} \\
(0.58)\end{array}$ & $\begin{array}{l}3.07^{* * *} \\
(0.51)\end{array}$ & $\begin{array}{l}2.86^{* * *} \\
(0.62)\end{array}$ & $\begin{array}{l}4.68^{* * *} \\
(1.28)\end{array}$ \\
\hline Close by & $\begin{array}{c}0.033 \\
(0.29)\end{array}$ & $\begin{array}{c}0.033 \\
(0.29)\end{array}$ & $\begin{array}{c}0.033 \\
(0.29)\end{array}$ & $\begin{array}{c}0.033 \\
(0.29)\end{array}$ & $\begin{array}{c}0.033 \\
(0.29)\end{array}$ & $\begin{array}{c}0.033 \\
(0.29)\end{array}$ & $\begin{array}{c}0.032 \\
(0.29)\end{array}$ \\
\hline Experienced & $\begin{array}{r}0.72^{*} \\
(0.43)\end{array}$ & $\begin{array}{r}0.72^{*} \\
(0.43)\end{array}$ & $\begin{array}{r}0.72^{*} \\
(0.43)\end{array}$ & $\begin{array}{c}0.73^{*} \\
(0.43)\end{array}$ & $\begin{array}{r}0.72^{*} \\
(0.43)\end{array}$ & $\begin{array}{r}0.72^{*} \\
(0.43)\end{array}$ & $\begin{array}{c}0.73^{*} \\
(0.43)\end{array}$ \\
\hline Large & $\begin{array}{c}-0.10 \\
(0.20)\end{array}$ & $\begin{array}{c}-0.10 \\
(0.20)\end{array}$ & $\begin{array}{c}-0.10 \\
(0.20)\end{array}$ & $\begin{array}{c}-0.10 \\
(0.20)\end{array}$ & $\begin{array}{c}-0.10 \\
(0.20)\end{array}$ & $\begin{array}{c}-0.10 \\
(0.20)\end{array}$ & $\begin{array}{c}-0.10 \\
(0.20)\end{array}$ \\
\hline Time between $(\ln )$ & $\begin{array}{c}0.25^{* * *} \\
(0.051)\end{array}$ & $\begin{array}{c}0.25^{* * *} \\
(0.051)\end{array}$ & $\begin{array}{c}0.25^{* * *} \\
(0.051)\end{array}$ & $\begin{array}{c}0.25^{* * *} \\
(0.051)\end{array}$ & $\begin{array}{c}0.25^{* * *} \\
(0.051)\end{array}$ & $\begin{array}{c}0.25^{* * *} \\
(0.051)\end{array}$ & $\begin{array}{c}0.25^{* * *} \\
(0.051)\end{array}$ \\
\hline x High price & $\begin{array}{c}0.28 \\
(0.81)\end{array}$ & & & & & & $\begin{array}{c}-0.044 \\
(0.97)\end{array}$ \\
\hline x Apartment & & $\begin{array}{c}-0.31 \\
(0.82)\end{array}$ & & & & & $\begin{array}{c}-0.30 \\
(0.97)\end{array}$ \\
\hline x High density & & & $\begin{array}{r}0.027 \\
(0.85)\end{array}$ & & & & $\begin{array}{r}0.070 \\
(0.90)\end{array}$ \\
\hline $\mathrm{x}$ Long sales time & & & & $\begin{array}{c}-2.77^{* * *} \\
(0.62)\end{array}$ & & & $\begin{array}{c}-2.75^{* * *} \\
(0.61)\end{array}$ \\
\hline x Fourth quarter & & & & & $\begin{array}{c}-1.64^{* *} \\
(0.74)\end{array}$ & & $\begin{array}{c}-1.52^{* *} \\
(0.75)\end{array}$ \\
\hline x Sold before 2008 & & & & & & $\begin{array}{c}-0.24 \\
(0.68)\end{array}$ & $\begin{array}{c}-0.30 \\
(0.74)\end{array}$ \\
\hline$R^{2}-$ within & 0.936 & 0.936 & 0.936 & 0.936 & 0.936 & 0.936 & 0.936 \\
\hline
\end{tabular}


broker), for the same property. If the switching between brokers is random, then we are able to eliminate the selection effects by comparing those house sales that involved a switch between broker types and the ones that did not. In order to investigate this, we employ an additional data set that is obtained from screenscraping the listing site where all houses are advertised. The data were collected in the period 2004-2010; an earlier version of the data set was used in Gautier et al. (2009).

We use the identification number of the first real-estate agent listing the house online, and indicate a sale as a "switch" when this agent is different from the agent at the time of sale. We find 3,680 transactions where the agent changed from a flat-fee type to a traditional broker, and 80 transactions where the agent changed from the traditional type to one with a flat fee.

The low number of switchers from traditional agents may be related to the difference in switching costs: traditional agents usually charge a termination fee as a compensation for the loss of income caused by the cancellation of the contract. The opposite occurs for sellers with a flat-fee agent: since they have already paid the fee up-front, their costs are sunk and hence there are no further monetary costs involved in changing to another agent. The low number of switchers from traditional to flat-fee is in line with Hendel et al. (2009), who also find a very low number of switches from sellers represented by a real-estate broker using the MLS and sellers who sell their own houses.

We create two additional dummy variables for the transactions: one for a transaction that started with a traditional agent and ended with a flat-fee agent, and one for a transaction that started with a flat-fee agent and ended with a traditional agent. 
Table 8: Sellers switching real-estate agents

Estimated coefficients on house- and broker characteristics. The sample period is 1985-2011, using houses that sold at least once since 2005. Only the coefficients on the broker dummies are reported, multiplied by 100. Clustered standard errors appear between parentheses (by neighborhood). *, **, *** denote significance at the $90 \%, 95 \%$ and $99 \%$ levels, respectively.

\begin{tabular}{|c|c|c|c|c|}
\hline \multirow[t]{2}{*}{ Dependent variable : } & \multicolumn{2}{|c|}{ Transaction price } & \multicolumn{2}{|c|}{ Time to sale } \\
\hline & $(1)$ & $(2)$ & $(3)$ & $(4)$ \\
\hline Flat-fee broker & $\begin{array}{l}2.73^{* * *} \\
(0.49)\end{array}$ & $\begin{array}{l}2.76^{* * *} \\
(0.49)\end{array}$ & $\begin{array}{r}-18.4^{* * *} \\
(4.60)\end{array}$ & $\begin{array}{c}-18.7^{* * *} \\
(4.61)\end{array}$ \\
\hline Close by & $\begin{array}{c}0.033 \\
(0.29)\end{array}$ & $\begin{array}{c}0.034 \\
(0.29)\end{array}$ & $\begin{array}{c}-5.09^{* *} \\
(1.92)\end{array}$ & $\begin{array}{c}*-5.11^{* * *} \\
(1.92)\end{array}$ \\
\hline Experienced & $\begin{array}{r}0.72^{*} \\
(0.43)\end{array}$ & $\begin{array}{c}0.72^{*} \\
(0.43)\end{array}$ & $\begin{array}{c}3.83^{* *} \\
(1.53)\end{array}$ & $\begin{array}{c}3.83^{* *} \\
(1.53)\end{array}$ \\
\hline Large & $\begin{array}{r}-0.10 \\
(0.20)\end{array}$ & $\begin{array}{c}-0.10 \\
(0.20)\end{array}$ & $\begin{array}{c}-7.12^{* *} \\
(1.78)\end{array}$ & $\begin{array}{c}*-1.11^{* *} \\
(1.78)\end{array}$ \\
\hline Time between $(\ln )$ & $\begin{array}{c}0.25^{* * *} \\
(0.051)\end{array}$ & $\begin{array}{c}0.25^{* * *} \\
(0.051)\end{array}$ & $\begin{array}{c}0.50^{* *} \\
(0.15)\end{array}$ & $\begin{array}{c}0.50^{* *} \\
(0.15)\end{array}$ \\
\hline Seller left flat-fee broker $(N=3680)$ & & $\begin{array}{c}-2.94 \\
(3.90)\end{array}$ & & $\begin{array}{c}22.7 \\
(49.6)\end{array}$ \\
\hline Seller came to flat-fee broker $(\mathrm{N}=80)$ & & $\begin{array}{c}0.48 \\
(0.48)\end{array}$ & & $\begin{array}{r}-13.2^{* *} \\
(5.40)\end{array}$ \\
\hline$R^{2}-$ within & 0.936 & 0.936 & 0.147 & 0.147 \\
\hline
\end{tabular}


The flat-fee effect is not changed, and there is only a significant effect for sellers who come to a flat-fee agent in terms of the time to sale. This is in sharp contrast with the results of Hendel et al. (2009), who find a strong positive effect for houses that are initially listed on the for-sale-by-owner website. Moreover, they conclude that whether the property gets ultimately sold by the sellers themselves makes no difference with respect to the price, if one controls for the fact that the property was originally placed on the for-sale-by-owner website. We find the oppo-

site: houses that were originally represented by a flat-fee broker and sold through the help of a traditional broker sell at an insignificantly lower price and with a longer time to sale. This does not completely rule out seller selection. It is still possible that (some) sellers are ignorant about their ability to sell and therefore randomly select themselves into one of the different agent types. Then, when they learn about their type, the sellers who learn that they are not good in selling their own property may switch to a traditional real-estate broker.

\subsection{Unsold items}

One concern is that our results are conditional on the outcome that the houses are sold. Unfortunately, our standard data set does not contain houses that were placed on the Funda website but were never sold. However, as already stated in Section 5.2, we also have a data set that we obtained from screen-scraping the Funda website. Hence, we can also use this website to investigate how many houses were placed at the website but never sold. One risk of this data set is that there may be some houses that we are not able to match with houses in our original data set and therefore we mistakenly consider them as unsold. Therefore, we use this method as a robustness 
check only. Another caveat of the data set is that we only have data for the period 2004 to $2008 .^{7}$

We find that 69.1 percent of the houses that ever appeared on the website got ultimately sold. In order to investigate whether relatively many sellers using a flat-fee broker withdrew their houses from the market, we estimated a logit model with a successful sale as dependent variable. Because our period of analysis is short and because we did not want to run the risk of not being able to match our (unsold) houses with houses that were sold in the past, we decided not to include any house fixed effects. The results of our logit regression are found in Table 9. We find that houses that were placed on the website by a flat-fee broker have a lower likelihood to be sold. The average derivative results in a 5.68 percent lower probability of a house being sold by such a broker. Apparently, even though sellers that use the services of a flat-fee broker sell more quickly (conditional on a successful sale), they also seem to quit their sales efforts faster than the sellers of houses who are traditional brokers.

An important question is whether this biases our final results. Of course it is impossible to know the counterfactual for unsold houses. However, it is likely that for those houses, prices would have been on average lower. In order to investigate this, we use the selection correction method in non-separable regression models developed in Fernandez-Val, et al. (2017). This correction method is based on the following model

$$
\log Y_{i}=g\left(X_{i}, Z_{i}, U_{i}\right)
$$

\footnotetext{
${ }^{7}$ We have the spidered data for a longer period but we do not want to run the risk that some houses were not sold yet at the latest date of our original data set.
} 
and

$$
\log T_{i}=h\left(X_{i}, Z_{i}, W_{i}\right)
$$

where $g$ and $h$ are unspecified functions. We assume here that $X_{i}$ represents the usual house characteristics and that $Z_{i}$ only indicates whether a sale was made by a flat-fee broker. The outcome variable $Y_{i}$ is price and $T_{i}$ is time on the market. The only assumptions that we make here is that $h$ increases with $W_{i}$ and that $X_{i}$ and $Z_{i}$ are independent from both $U_{i}$ and $W_{i}$ in case that all houses are observed. However, we assume that $Y_{i}$ is only observed in the case that $T_{i}<C_{i}$ for some random $C_{i}$, which is independent of $X_{i}, Z_{i}, U_{i}$ and $W_{i}$. For this case, it can be shown that the distribution of $V_{i} \equiv F_{T}\left(T_{i} \mid X_{i}, Z_{i}\right)$ is a control variable for $U_{i} \mid X_{i}, Z_{i}, T_{i}<C_{i}$. We estimate the control variable using a mixed proportional hazards rate model with a piecewise constant baseline hazard and use the integrated hazard to calculate the distribution function (see Donald et al., 2000). Then, we estimate the local average structural function, $\mu(x, z, v)=\mathbb{E}\left(\log Y_{i} \mid X_{i}=x, Z_{i}=z, V_{i}=v\right)$ by the predictions of a non-parametric series regression of $\log Y_{i}$ on $X_{i}, Z_{i}$ and the control variable $V_{i}$. The average treatment effect on the treated, i.e.

$$
\mathbb{E}_{X_{i}, V_{i} \mid Z_{i}=1}\left(\mu\left(X_{i}, 1, V_{i}\right)-\mu\left(X_{i}, 0, V_{i}\right)\right)
$$

can then be estimated by averaging over the values of $V_{i}$,

$$
\sum_{i=1}^{n}\left(\widehat{\mu}\left(X_{i}, 1, \widehat{V}_{i}\right)-\widehat{\mu}\left(X_{i}, 0, \widehat{V}_{i}\right)\right) \mathbf{1}\left(Z_{i}=1\right) / \sum_{i=1}^{n} \mathbf{1}\left(Z_{i}=1\right)
$$

where $n$ is the number of observations. This procedure is valid as long as we assume that houses are more likely to be withdrawn from the market (for any elapsed time 
Table 9: Results of the unsold items

Estimated coefficients on the broker dummy variables. The sample period is 2004-2008. Only the coefficients on the broker dummies are reported (multiplied by 100). Standard errors appear between parentheses. * $* *, * * *$ denote significance at the $90 \%, 95 \%$ and $99 \%$ levels, respectively.

\begin{tabular}{lrrrr}
\hline \hline & $\begin{array}{r}\text { Logit } \\
\text { Sold }\end{array}$ & MPH & $\begin{array}{r}\text { ATT } \\
\text { uncor- } \\
\text { rected }\end{array}$ & $\begin{array}{r}\text { ATT } \\
\text { cor- } \\
\text { rected }\end{array}$ \\
\hline \hline Flat-fee & -0.275 & -0.016 & 3.02 & 2.88 \\
& $(0.019)$ & $(0.015)$ & $(0.25)$ & $(0.24)$ \\
\hline \hline
\end{tabular}

on the market) when a flat-fee broker is used than when a traditional broker is used. This seems a valid assumption based on our earlier results. Note that our method is similar to Vella (1993), but we do not make any assumption on the relationship between $Y_{i}, X_{i}$ and $Z_{i}$, nor on the distribution of $U_{i}$ and $W_{i}$. Note also that we do not need an exclusion restriction for this case.

The idea behind our method is simply that we impose the apparently more restrictive truncation process of the flat-fee brokers on the duration distribution of the traditional brokers. In addition, we also impose this through the relationship between the unobserved components (i.e. houses that take longer to sell have in general less attractive unobserved characteristics) on the price distribution of these traditional brokers. This results in the counterfactual distribution that we would observe in the case that traditional brokers would have stopped their sales effort at the same speed as the flat-fee brokers do. This is identified based on the assumption of the higher level of truncation for the flat-fee brokers.

The results of this exercise are reported in Table 9. The second column of that table reports the coefficient of the mixed-proportional hazards rate model. The coefficient is negative but insignificant and extremely small, implying that when 
taking the unsold items into account, both broker types sell at almost the same speed. The average treatment effect equals 3.02 percent in the case that we do not correct for selective attrition. This amount is only slightly reduced to 2.88 percent in the case that we use the correction method. We can conclude from this that, even though the traditional real-estate agents are less likely to withdraw difficult-to-sell houses, this cannot fully explain the difference in selling prices between these two types of agents.

\subsection{Neighborhood selection effects}

The broker effect could be caused by unobserved seller sophistication that is correlated with both broker choice and sales performance. Data constraints keep us from directly testing this relation. Specifically, we lack information on seller characteristics. However, an indirect test is possible if we assume that seller sophistication is correlated within neighborhoods. Then, neighborhoods with many flat-fee sellers will also have more sophisticated sellers who sell via a traditional broker, since seller sophistication has a common component within the neighborhood. The resulting flat-fee effect will be smaller than average.

We perform the following exercise to investigate this: instead of running our fixed-effect model (1) on the full sample of observations, we only include the observations that have at least a certain number of transactions performed by a flat-fee broker in the corresponding neighborhood of that observation. Figure 2 illustrates the results of such an exercise where the $x$-axis of that figure equals the minimum number of transactions that the corresponding neighborhood must have in order to be included in the regression. 
Figure 2: Conditioning on number of flat-fee transactions

The coefficient on the flat-fee dummy (grey bars) is presented for samples of transactions with an increasing minimum number of flat-fee transactions per neighborhood. The estimation resembles the third column of Table 4 (i.e., with house price fixed effects, house characteristics, province-year interactions and broker variables). The maximum number of fixed-price transactions in a neighborhood is 88 , which occurs in exactly one neighborhood. The dashed lines represent the 95 percent confidence interval. The solid line indicates the fraction of houses involving flat-fee brokers in the estimation sample.

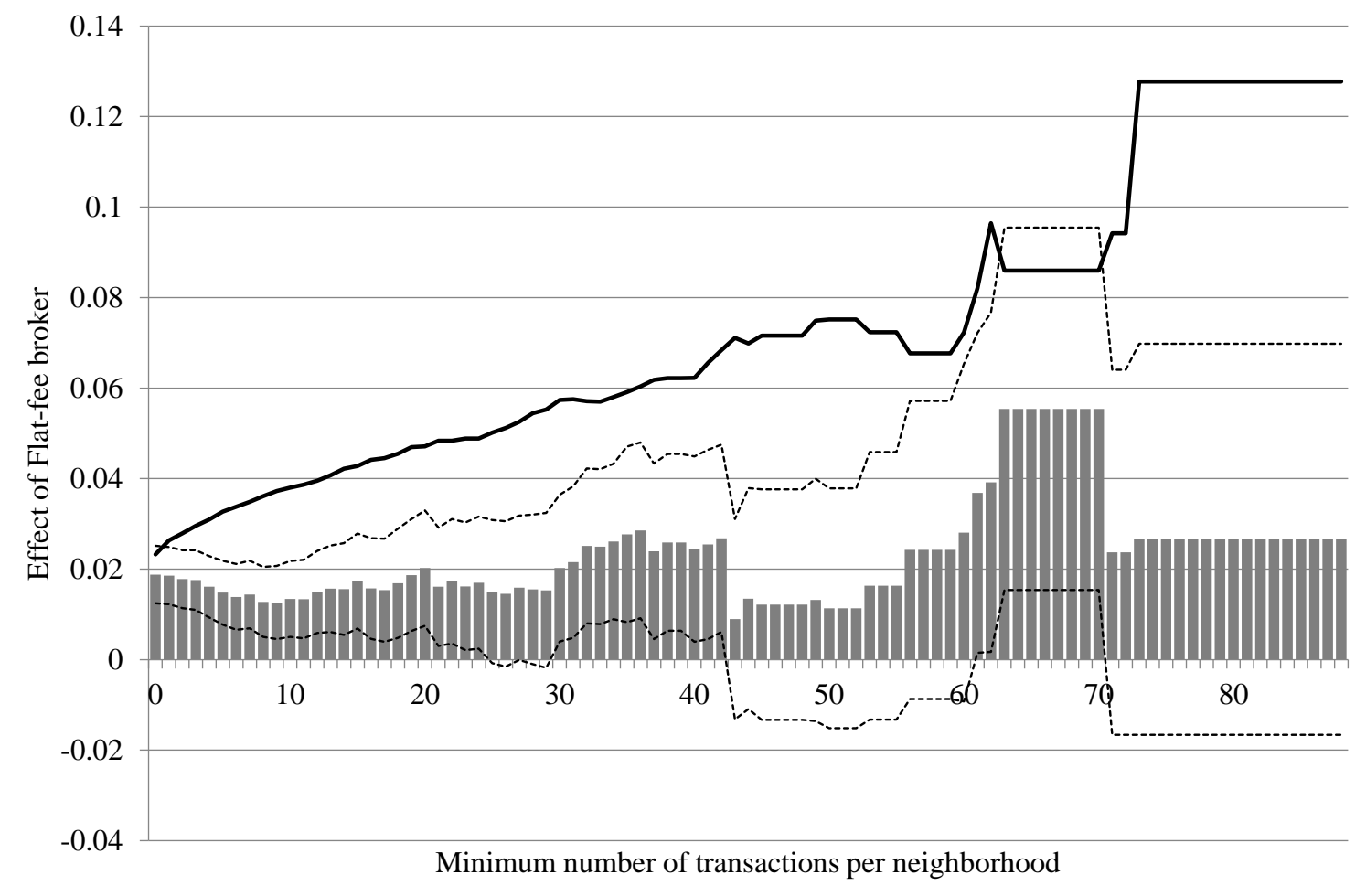


The estimates for the flat fee are depicted by the gray bars in Figure 2. The dotted lines show the 95 percent confidence bounds. We conclude that the effect is not decreasing in the number of transactions per neighborhood, which again suggests that our results are not driven by the sorting of sophisticated sellers into flat-fee brokers. Figure 2 also shows that there is a very strong relationship between the number and percentage of transactions represented by a flat-fee broker. Hence, our results are not affected by the size of the neighborhoods.

We obtain similar results if we condition on a sample of transactions with an estimated high probability of having a flat fee. Predicted probabilities are estimated using a regression with flat-fee broker as dependent variable, taking account of all house characteristics as control variables, and using neighborhood fixed effects. The 10 percent of transactions with the highest estimated probability are then used in a regression with the transaction price as dependent variable, as was done above. In this specification, the estimated effect of a flat fee is 2.2 percent, which is slightly lower than the coefficient of 2.7 percent in Table 4 with neighborhood fixed effects - but it is still highly significant.

We also tested whether houses sold by flat-fee brokers are more likely to be sold by the same type of broker again. This turns out not to be the case: an initial sale by a flat-fee agent leads to a subsequent sale in which a flat-fee broker is used in only $0.62 \%$ of the cases. This indicates that the choice of broker has little relation with the house or neighborhood. 


\section{Discussion}

Houses sold with flat-fee agents seem to exhibit a consistent pattern: (i) they sell at a higher transaction price and (ii) they sell faster (at least conditional on sale). Proximity, experience, and size of the broker have no effect on the realized transaction price, and only a negligible effect on the time to sale. Below, we discuss several potential explanations for our results: (i) market power, (ii) seller selection effects, (iii) asymmetric information, and (iv) broker incentives.

\subsection{Market power of brokers}

The fact that a flat fee leads to better sales performance suggests that the market for traditional real-estate agents is not competitive. We are hardly the first to point this out; see for example, Levitt and Syverson (2008a) and Bernheim and Meer (2013). Even in the financial industry there is clear evidence of persistent inefficiency in the allocation of retail investor funds to mutual funds; see Del Guercio et al. (2010). The explanation of limited financial literacy by clients is potentially magnified in the housing market, which consists of high-stakes transactions that participants engage in only a few times in their lifetime.

\subsection{Seller selection effects}

The main alternative explanation for our large effect of using a flat-fee broker is that what we measure is driven by the selection of sophisticated sellers. In our robustness section we did not, however, find any evidence for this.

Similar issues play a role in the demand for full-service brokers within US 
defined-contribution plans; see Chalmers and Reuter (2013). The participants who use a broker are usually younger, lower educated and less comfortable with making financial decisions. The specific selection effect that comes with age is also reported by Agarwal et al. (2009), who find that, across many financial decisions, people make the best decisions around the age of 53. Our estimations therefore use a control variable that captures the number of years between sales although this only partly captures the age-effect of the seller. If sellers are on average older than buyers, then an age-induced choice for a cheaper (or more efficient) broker might correlate with better sales performance.

Another potential selection effect is that sellers with high opportunity costs for conducting the viewings choose a traditional broker to do it for them. However, based on the price difference of 2.7 percent and a transaction fee for the traditional real-estate agents of 2 percent, our results indicate a difference of roughly 5 percent of the sales price. For an average sales price of 200,000 Euro, this implies a difference of 10,000 Euro in terms of the two different types of brokers. It is unlikely that almost 98 percent of the sellers (i.e. those using a traditional real-estate broker), have such a high level of opportunity costs. To place the 10,000 Euro into perspective, note that the marginal tax rate in the Netherlands equals 42 percent for a median income of 35,000 in 2015 . Hence, this explanation requires that the opportunity costs must be roughly half a year of labor income, which seems unlikely.

Better negotiation skills by some sellers, or tougher bargaining are not likely explanations because both types of brokers advise on the list price and perform the negotiations at arms-length. Also, we find that using a flat fee has a similar effect on list prices as on transaction prices; it is therefore not the case that list prices are used more strategically by one type of broker. Finally, as reported in the previous 
section, our findings hold for different subsets of sellers and neighborhoods.

\subsection{Mitigation of Asymmetric Information}

Under the flat-fee structure, sellers are responsible for the viewings themselves. The personal interaction of hosting the viewings could convey information that decreases the asymmetric information problem. The face-to-face interaction between buyer and seller, and the factual knowledge about the house and the neighborhood may induce the buyer to pay more for the house than when faced with a broker. Lewis (2011) finds that the market for cars on eBay functions, largely because sellers give concrete and verifiable information about the particular car they are selling. In the housing market, viewings hosted by the seller could have the same effect: the seller can provide details on maintenance and neighborhood characteristics that a typical real-estate agent would find much harder to provide. Note that this explanation is consistent with a non-competitive real-estate market.

\subsection{Broker specialization}

The better performance of flat-fee brokers could reflect a more efficient division of labor: flat-fee brokers specialize in the skills that are most relevant for transaction performance, such as price setting, salesmanship and negotiation. The seller takes on the labor-intensive, but low-skilled, work of hosting viewings, generally providing better information about the house and displaying some salesmanship. In addition, the variable costs of rejecting an offer are lower than for full-service brokers, as the costs of organizing and conducting the viewings are borne by the seller and not the agent. The lower opportunity costs of rejecting an offer could explain why 
transaction prices are higher using a flat fee.

Note that the last two explanations imply a potential efficiency gain that remains largely unexploited, given the low market share of flat-fee brokers - the persistence of which could be explained by limited attention, limited rationality, inexperience of sellers or a combination of these factors. The existence of persistent inefficiency in a competitive market is not impossible, as documented by Cho and Rust (2010), who give evidence for this in the rental car market.

\section{$7 \quad$ Final remarks}

After an online centralized listing service for real estate was introduced in 2001, it became profitable for flat-fee brokers to enter the Dutch market. Brokers charge the flat fee up-front and delegate the viewings to the sellers. Flat-fee brokers are thus a low-cost alternative to traditional full-service brokers. Our analysis provides a strong statistical evidence that the performance of flat-fee brokers is better: they obtain higher sales prices, at lower sales times. Consequently, the profits of traditional full-service brokers partly reflect rents.

The existence of a large rent-seeking component in the compensation of traditional brokers is consistent with limited price competition. The strong performances of flat-fee brokers has not (yet) eliminated traditional brokers, possibly due to limited attention and inexperience of sellers in the housing market. 


\section{References}

Agarwal, S., J.C. Driscoll, X. Gabaix And D. Laibson (2009). "The age of reason: Financial decisions over the life cycle and implications for regulation", Brookings Papers on Economic Activity, Fall 2009, 51-117.

Albrecht, J., P.A. Gautier And S. Vroman (2016), "Directed search in the housing market", Review of Economic Dynamics, 19, 218-31.

Bergstresser, D., J.M. Chalmers and P. Tufano (2009), "Assessing the costs and benefits of brokers in the mutual fund industry", Review of Financial Studies, 22, 4129-56.

Bernheim, B.D. And J. MeER (2013), "Do real estate brokers add value when listing services are unbundled?", Economic Inquiry, 51, 1166-82.

Butler, A.W. (2008), "Distance still matters: Evidence from municipal bond underwriting", Review of Financial Studies, 21, 763-84.

CASE, K.E. AND R.J. ShIller (1989), "The efficiency of the market for singlefamily homes", American Economic Review, 79, 125-37.

Cho, S. And J. Rust (2010), "The flat rental puzzle", Review of Economics Studies, 77, 560-94.

Coles, M.G., AND E. Smith (1998), "Marketplaces and matching", International Economic Review, 39, 239-54.

Chalmers, J. And J. Reuter (2013), "What is the impact of financial advisors on retirement portfolio choices and outcomes?", working paper, Boston College.

Del Guercio, D., J. Reuter and P.A. Tkac (2010), "Broker incentives and 
mutual fund market segmentation", working paper, Boston College.

Donald, S.G. D.A. Green, H.J. Paarsch (2000), "Differences in wage distributions between Canada and the United States: An application of a flexible estimator of distribution functions in the presence of covariates", Review of Economic Studies, 67, 609-33.

Fernandez-Val, I., A.P. van Vuuren and F. Vella (2017), "Selection effects of nonseparable models using a control function approach", working paper, University of Gothenburg. '

Gautier, P.A., A.H. Siegmann, A.P. van Vuuren (2009), "Terrorism and attitudes towards minorities: The effect of the Theo van Gogh murder on house prices in Amsterdam", Journal of Urban Economics, 65, 113-26.

HAN, L. And S.H. Hong (2011), "Testing cost inefficiency under free entry in the real estate brokerage industry", Journal of Business and Economic Statistics, $29,564-78$.

Hendel, I., A. Nevo And F. Ortalo-Magné (2009), "The relative performance of real estate marketing platforms: MLS versus FSBOmadison.com", American Economic Review, 99, 1878-98.

Ivković, Z. AND S. WeisBenner (2005), "Local does as local is: Information content of the geography of individual investors' common stock investments", The Journal of Finance, 60, 267-306.

Levitt, S. And C. Syverson (2008a), "Antitrust implications of home seller outcomes when using flat-fee real estate agents", working paper, University of Chicago. 
Levitt, S. AND C. Syverson (2008b), "Market distortions when agents are better informed: The value of information in real estate transactions", Review of Economics and Statistics, 90, 599-611.

LEWIS, G. (2011), "Asymmetric information, adverse selection and online disclosure: The case of eBay motors" American Economic Review, 101, 1535-46.

NADEL, M. (2006), "A critical assessment of the traditional real estate broker commission rate structure", Cornell Real Estate Review, 5, 26-46.

OECD (2007), "Improving competition in real estate transactions", Paris.

OYER, P. (1998), "Fiscal year ends and nonlinear incentive contracts: The effect on business seasonality" Quarterly Journal of Economics, 13, 149-85.

Rutherford, R. AND A. YAVAs (2012), "Discount brokerage in residential real estate markets, Real Estate Economics, 40, 508-35.

Rutherford, R.C., T. Springer And A. Yavas (2005), "Conflicts between principals and agents: Evidence from residential brokerage", Journal of Financial Economics, 76, 627-65.

StACEY, D.G. (2013), "Information, commitment, and separation in illiquid housing markets", working paper, Ryerson University, Toronto,.

Teo, M. (2009), "The geography of hedge funds", Review of Financial Studies, 22, $3531-61$.

VELlA, F. (1993), "A simple estimator for simultaneous models with censored endogenous regressors", International Economic Review, 34, 441-57.

White, L.J. (2006), "The residential real estate brokerage industry: What would more vigorous competition look like?", working paper, New York University. 